\title{
Relationship of Inhibition of Prostaglandin Biosynthesis by Analgesics to Asthma Attacks in Aspirin-sensitive Patients
}

\author{
A. SZCZEKLIK, R. J. GRYGLEWSKI, G. CZERNIAWSKA-MYSIK
}

British Medical fournal, 1975, 1, 67-69

\begin{abstract}
Summary
Eleven patients with asthma and aspirin hypersensitivity have been challenged with eight non-steroidal antiinflammatory drugs. Each drug was given by mouth in at least three different doses and the patients' symptoms and peak expiratory flow (PEF) rates were observed over a three-hour period. Indomethacin $5 \mathrm{mg}$ caused bronchoconstriction in all patients. Therapeutic doses of mefenamic or flufenamic acid caused bronchoconstriction in most patients. Phenylbutazone $200-400 \mathrm{mg}$ induced a moderate fall in PEF. There were no reactions to therapeutic doses of salicylamide, paracetamol, benzydamine, and chloroquine. Microsomal prostaglandin synthetase activity was inhibited by aspirin,indomethacin, mefenamic acid, flufenamic acid, and phenylbutazone. The other four drugs had no inhibitory effect.

We suggest that precipitation of attacks in asthmatic patients hypersensitive to certain anti-inflammatory drugs is related to the drug's ability to inhibit prostaglandin biosynthesis.
\end{abstract}

\section{Introduction}

Asthmatic attacks induced by aspirin begin between 20 minutes and two hours after the drug is taken and are sometimes accompanied by rhinorrhoea and angioneurotic oedema. Typically, aspirin-sensitive asthma occurs in middle-aged women with pre-existing vasomotor rhinitis and nasal polyps. Wheezing and increased obstruction to airflow may also develop in aspirinsensitive patients after taking other analgesics-for example, indomethacin (Vanselow and Smith, 1967). The prevalence of aspirin hypersensitivity among asthmatics has been reported as varying from $2.3 \%$ (Pearson, 1963) to $16 \%$ (McDonald et al., 1972). Its pathogenesis is unknown. Nevertheless, the discovery by Vane (1971) that aspirin and other analgesics (Flower et al., 1972) inhibit the biosynthesis of prostaglandins offers a rational explanation for their mode of action.

This paper reports a study in which we measured the effect of each of eight non-steroidal anti-inflammatory drugs on lung function in aspirin-sensitive patients and compared it with the ability of the drugs to inhibit the activity of microsomal prostaglandin synthetase.

\section{Patients and Methods}

Eleven asthmatic patients, eight women and three men, were studied. Their ages ranged from 33 to 66 years (mean 46 years) and all were hypersensitive to aspirin. In six the hypersen-

Copernicus Medical Academy, Skawinska 8, Krakow, Poland

A. SZCZEKLIK, M.D., Head of Department of Allergy and Clinical Immu-

Gology

R. J. GRYGLEWSKI, M.D., Professor of Pharmacology sitivity had appeared on average five years after the onset of asthma. In four the first attack of asthma had coincided with taking an aspirin tablet. Only one patient had had aspirin sensitivity for many years before respiratory symptoms appeared. Of the 11 patients studied 10 gave a history of an asthmatic attack after taking one tablet of aspirin, while in one patient angioneurotic oedema was the dominant reaction. A history of recurrent pulmonary infection and transient urticaria was common in all the patients. Ten had chronic rhinitis and six had nasal polyps. In seven patients the serum IgE levels, measured by a radioimmunoabsorbence technique (Pharmacia Ltd., Uppsala), ranged from 760 to $1,800 \mathrm{U} / \mathrm{ml}$ (mean 1,122 $\mathrm{U} / \mathrm{ml}$ ). In 10 healthy subjects the levels were from 100 to $930 \mathrm{U} / \mathrm{ml}$. Three of the 11 patients needed low-dose corticosteroid maintenance therapy to control their asthma. Six others had received corticosteroids for brief periods.

\section{CHALLENGE TESTS}

Patients were challenged with the following drugs given by mouth in the following doses: indomethacin 1, 5, and $25 \mathrm{mg}$; mefenamic acid 10,50 , and $250 \mathrm{mg}$; flufenamic acid 20,100 , 200 , and $300 \mathrm{mg}$; phenylbutazone $10,50,100,200$, and $400 \mathrm{mg}$; salicylamide 10,100 , and $500 \mathrm{mg}$; paracetamol 10,100, and $300 \mathrm{mg}$; benzydamine 1,5 , and $50 \mathrm{mg}$; and chloroquine 25 , 100 , and $250 \mathrm{mg}$. Lactose in $100-\mathrm{mg}$ doses was used as a placebo. All drugs and the placebo were in colourless gelatin capsules. The challenge tests were done in the morning after a light breakfast. The patients were told that various drugs were to be tested but the type of drug was unknown to them. Bronchodilator drugs were withdrawn eight hours beforehand.

Subjective symptoms, the findings on chest examination, and the pulse rate, blood pressure, and peak expiratory flow (PEF) were recorded before giving the drug and again half an hour and one, two, and three hours later. Routine clinical observation was continued for 24 hours. PEF was measured by a Wright peak flow meter as described by Gregg and Nunn (1973). The highest of three successive values was accepted. A decrease in PEF of more than $15 \%$ was considered positive.

Only one drug in one dose was tested on any one day. No set order of drugs was used and the placebo day varied. The tests began with the smallest dose of the drug. If there was no response the dose was increased at the next challenge. Any mild or equivocal reaction was followed by a four-day, doubleblind study in which the drug and placebo were given randomly.

The purpose and possible hazards (hypersensitive reactions) of the challenges were fully explained to the patients. All consented to take part since they stood to benefit from the possible discovery of an analgesic which would be a safe alternative to aspirin for them. Any reactions were immediately relieved by the intravenous injection of aminophylline or hydrocortisone hemisuccinate or orciprenaline inhalation.

\section{ENZYME ASSAY}

Prostaglandin synthetase for assay was obtained from bovine 
seminal vesicle microsome (B.S.V.M.) (Takeguchi et al., 1971). B.S.V.M. 1-2 mg together with arachidonic acid $33 \mu \mathrm{mol}$, glutathione $160 \mu \mathrm{mol}$, and hydroquinone $45 \mu \mathrm{mol}$ in $2 \mathrm{ml}$ of $100 \mathrm{mmol}$ phosphate buffer $\mathrm{pH} 7 \cdot 4$ were incubated for 20 minutes at $37^{\circ} \mathrm{C}$. Radiochromatography showed that prostaglandin $\mathrm{E}_{2}$ formed $90 \%$ of the resulting product. Bioassay with rat stomach strip (Flower et al., 1972) showed its average enzymic activity to be equivalent to $1,448 \pm 150 \mathrm{ng}$ of prostaglandin $\mathrm{E}_{2}$ per $\mathrm{mg}$ of microsomal protein.

Drugs at concentrations ranging from $0.01 \mu \mathrm{mol}$ to $1 \mathrm{mmol}$ were added to the incubation mixture five minutes before the arachidonic acid. The concentration of a drug that inhibited the enzymic activity by a half $\left(\mathrm{IC}_{50}\right)$ was calculated from the regression equation: $y=$ per cent. of inhibition of enzymic activity versus $\mathbf{x}=$ logarithm of drug concentration.

\section{BINDING TO ALBUMIN}

Binding of drugs to hydrophobic sites of bovine serum albumin (B.S.A.) as spotted by 8-anilino-1-naphthalene-sulphonate (ANS) was estimated spectrofluorometrically (Daniel and Weber, 1966) by an Atomic-Baird spectrofluorometer. The excitation wavelength was $380 \mathrm{~nm}$ and maximum fluorescence was read at $485 \mathrm{~nm}$. B.S.A. at a concentration of $10 \mu \mathrm{mol}$ in $2 \mathrm{ml}$ of $100 \mathrm{mmol}$ phosphate buffer $\mathrm{pH} 7.0$ was incubated at $22^{\circ} \mathrm{C}$ for 30 minutes in the presence of different concentrations (0.01-10 mmol) of a drug. ANS was then added to give a final concentration of $40 \mu \mathrm{mol}$. Fluorescence-quenching in the ANS-B.S.A. complex by a drug was expressed in $\mathrm{IC}_{50}$ values.

The ratio of $\mathrm{IC}_{50}$ for quenching fluorescence in the ANS-B.S.A. complex to the $\mathrm{IC}_{50}$ for inhibiting prostaglandin synthetase ( $Q$ ratio in table II) was taken as the index of the inhibitory action of a drug on prostaglandin generation in vivo (Gryglewski, unpublished results).

\section{Results}

\section{CHALLENGE TESTS}

Indomethacin.-Challenge with indomethacin was positive in all the patients (table I). The reaction, which began between 30 and 150 minutes after ingestion of the drug, was characterized by profuse rhinorrhoea, conjuctival injection, and an acute asthmatic attack. There was a fall in PEF ranging from $42 \%$ to $85 \%$. In four patients the reaction occurred after a 1-mg dose, in six after a $5-\mathrm{mg}$ dose, and in one after a $25-\mathrm{mg}$ dose (see fig.).

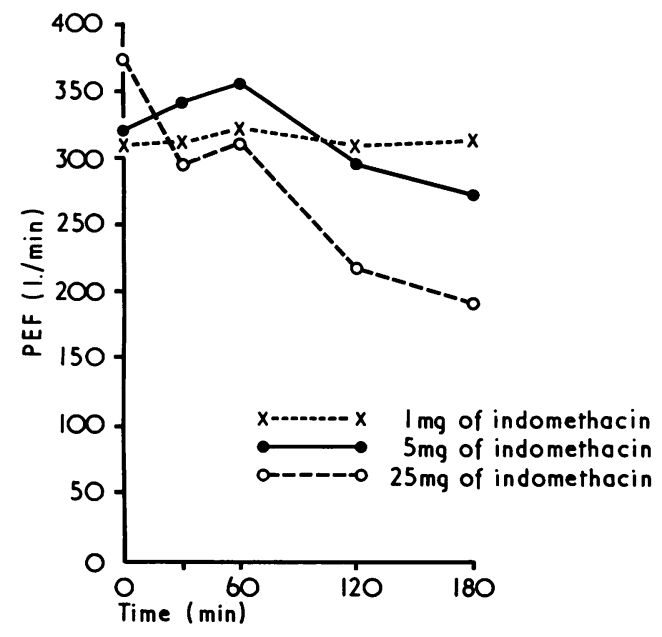

Results of challenge with indomethacin in one patient: $1 \mathrm{mg}=$ no reaction; $5 \mathrm{mg}=$ rhinorrhoea without wheezing after three hours; $25 \mathrm{mg}=$ acute asthma attack.
TABLE I-Results of Challenge with Indomethacin, Mefenamic Acid, Flufenamic Acid, and Phenylbutazone

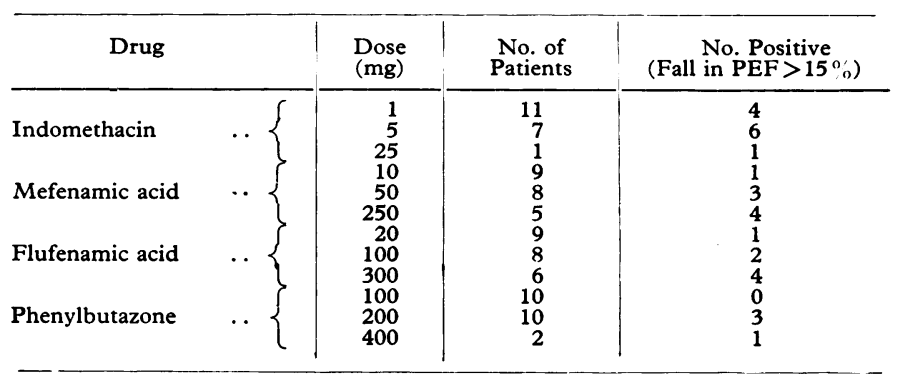

Mefenamic Acid.-Nine patients received $10 \mathrm{mg}$ of mefenamic acid (table I). Only one reacted positively. The remaining eight patients received a 50-mg dose. Three developed tightness in the chest or wheezing and their PEF decreased by $16 \%, 22 \%$, and $50 \%$ respectively. Four of the remaining five patients developed asthma when given $250 \mathrm{mg}$. One had no reaction. Other reactions to mefenamic acid were lacrimation, rhinorrhoea, and flushing.

Flufenamic Acid.-Only one out of nine patients given a 20-mg dose of flufenamic acid had a positive reaction (table I). Two of the remaining eight patients who were challenged with $100 \mathrm{mg}$ had an asthma attack within three hours. In one of them the PEF fell by $69 \%$ and isoprenaline and aminophylline were needed to reverse it. The remaining six patients received a 300-mg dose. In four the PEF decreased after two hours by $16 \%, 24 \%, 38 \%$, and $40 \%$ respectively.

Phenylbutazone.-Phenylbutazone in doses of 10 and $100 \mathrm{mg}$ produced neither untoward reactions nor a fall in PEF in any of the 10 patients studied (table I). After challenge with $50 \mathrm{mg}$ one patient developed rhinorrhoea and another angioneurotic oedema of the lip. After $200 \mathrm{mg}$ decreases in PEF of $14 \%, 22 \%$, and $27 \%$ were found in three of the 10 patients. Two patients who showed no response to $200 \mathrm{mg}$ of phenylbutazone were challenged with $400 \mathrm{mg}$. After six hours one of them developed wheezing and rhinorrhoea preceded by a fall in PEF.

Salicylamide, Paracetamol, Benzydamine, and Chloroquine.None of the 11 patients who received the maximum doses of salicylamide $(500 \mathrm{mg})$, paracetamol $(300 \mathrm{mg})$, benzydamine (50 $\mathrm{mg}$ ), and chloroquine (250 $\mathrm{mg}$ ) developed signs of hypersensitivity; nor was their PEF reduced by more than $13 \%$. The results of a further challenge with $100 \mathrm{mg}$ of benzydamine in one patient and with $600 \mathrm{mg}$ of paracetamol in another were also negative.

Placebo.-Challenge with placebo produced no signs of reaction or changes in PEF in any patient.

\section{TESTS IN VITRO}

The results of in-vitro testing of the inhibitory action of the drugs are shown in table II. The first five listed inhibited prostaglandin synthetase activity and displaced ANS from albumin.

TABLE II-In-vitro Activity of Anti-inflamatory Drugs

\begin{tabular}{|c|c|c|c|}
\hline Drug & 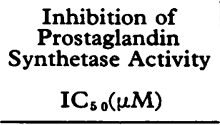 & $\begin{array}{c}\text { Quenching of } \\
\text { Fluorescence } \\
\text { in ANS-BSA Com- } \\
\text { plex } \\
\mathrm{IC}_{50}(\mu \mathrm{M}) \\
\end{array}$ & $\begin{array}{c}\text { Quenching: Inhibi- } \\
\text { tion Ratio } \\
\text { (Q) }\end{array}$ \\
\hline 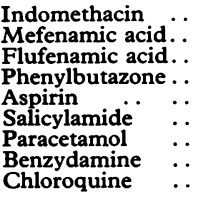 & $\begin{array}{r}0 \cdot 10 \\
0 \cdot 25 \\
8 \cdot 30 \\
148 \\
164 \\
>1,000 \\
>1,000 \\
>1,000 \\
>1,000\end{array}$ & $\begin{array}{r}140 \\
160 \\
80 \\
1,000 \\
5,600 \\
>10,000 \\
>10,000 \\
>10,000 \\
>10,000\end{array}$ & $\begin{array}{c}1,400 \\
640 \\
9 \cdot 6 \\
6 \cdot 8 \\
34 \\
= \\
=\end{array}$ \\
\hline
\end{tabular}


The estimated ability of these drugs to inhibit biosynthesis of prostaglandins in vivo, as predicted by the $Q$ ratio, diminished in the following order: indomethacin $>$ mefenamic acid >aspirin $>$ flufenamic acid $>$ phenylbutazone. Salicylamide, paracetamol, benzydamine, and chloroquine neither inhibited enzyme activity nor were they bound to albumin.

\section{Discussion}

We have shown that flufenamic acid as well as indomethacin and mefenamic acid may precipitate asthmatic attacks in aspirinsensitive patients. Phenylbutazone has not usually been regarded as harmful to aspirin-sensitive patients (Samter and Beers, 1967), but Smith (1971) reported a mean reduction in $\mathrm{FEV}_{1}$ of $8.4 \%$ in three aspirin-sensitive patients after a 100 -mg dose. Challenge with $50 \mathrm{mg}$ of phenylbutazone in 10 of our patients produced rhinorrhoea in one and angioneurotic oedema in another. Challenge with $200 \mathrm{mg}$ induced a mean fall in PEF of $21 \%$ in three, though none had dyspnoea. Phenylbutazone is therefore not a drug which can safely be recommended for aspirin-sensitive patients, though adverse reactions are infrequent and less pronounced than those induced by indomethacin, aspirin, or fenamates.

Aspirin, indomethacin, fenamates, and phenylbutazone have different chemical structures but in our study all of them inhibited biosynthesis of prostaglandins. All of them also precipitated the asthma attacks in aspirin-sensitive patients. Salicylamide, benzydamine, chloroquine, and paracetamol did not inhibit prostaglandin biosynthesis in the concentrations used in our study and no untoward reactions to these drugs were noted.

The mechanism of adverse reactions to aspirin and some other anti-inflammatory drugs remains unknown. Allergy has been excluded by extensive immunological studies (Girard et al., 1969-70; Yurchak et al., 1970). The differences in chemical structure of drugs which precipitate asthmatic attacks in aspirinsensitive patients make immunological cross-reactivity most unlikely (British Medical fournal, 1973). Other theories are that there is pre-existing injury of kinin receptors (Samter and Beers, 1968), that aspirin directly activates the complement system (Yurchak et al., 1970), and that aspirin activates the multienzymic system when there is a deficiency of a hypothetical enzyme inhibitor (Yurchak et al., 1970).

Our study showed the following. (1) Five out of nine antiinflammatory drugs inhibited prostaglandin biosynthesis in vitro, and only these five drugs (aspirin, indomethacin, mefenamic acid, flufenamic acid, and phenylbutazone) induced a fall in PEF or adverse reactions in aspirin-sensitive asthmatic patients. (2) The ability of four of these drugs (aspirin was not used for challenge) to induce bronchoconstriction was the same as their estimated power to inhibit prostaglandin synthesis in vivo. (3) Though susceptibility to adverse reactions to inhibitors of prostaglandin biosynthesis is an individual feature it was uniform for all the aspirin-like drugs tested in any patient. (4) The severity of reactions to these drugs was intensified by an increase in their dosage.

We therefore suggest that the pathogenesis of intolerance to aspirin, indomethacin, and fenamates in certain asthmatic patients is closely related to the inhibition of prostaglandin biosynthesis by these drugs. The role of prostaglandins in the lung has been intensively studied (Smith, 1973). Horton (1969) suggested that asthmatic bronchospasm may be due to overproduction of the bronchoconstrictor prostaglandins $F$ at the expense of the bronchodilator prostaglandins $\mathrm{E}$. This hypothesis is contradicted by the fact that asthmatic patients are abnormally sensitive to the bronchoconstrictor effect of exogenous prostaglandin $\mathrm{F}_{2 \alpha}$ (Mathé et al., 1973).

It is difficult to explain why only some asthmatic patients react to aspirin-like drugs while most tolerate or even benefit from them (Smith, 1973). We speculate that in asthmatic patients who are insensitive to aspirin-like drugs the action of endogenous histamine is mainly balanced by the $\beta$-adrenergic system while prostaglandins play a minor part in maintaining the patients' wellbeing. In aspirin-sensitive asthma histamine acts to some extent in the same way as the prostaglandins $F$, and the action of both bronchoconstrictors is balanced mainly by prostaglandins $\mathrm{E}$ and to a less extent by the $\beta$-adrenergic tone. Thus in the first group of patients the suppression of prostaglandins has no serious consequences while in the second group it opens the way for histamine action.

There is some indirect evidence to support our assumption. Samter and Beers (1968) found the threshold bronchoconstrictor dose of histamine in aspirin-sensitive patients to be significantly smaller than that in a similar group of "regular" asthmatic patients. On the other hand, we have found that aspirinsensitive patients tolerate much larger doses of prostaglandin $\mathrm{F}_{2 \alpha}$ in terms of reduction in PEF than do aspirin-insentitive patients. Thus in aspirin-sensitive asthma a decrease in histamine tolerance is accompanied by an increase in tolerance to prostaglandin $\mathrm{F}_{2 \alpha}$. This fits our hypothesis, because when the tissues are unable to produce or store enough endogenous mediator the biological action of the mediator is enhanced when it is applied exogenously. The reverse is also true (Cannon's phenomenon).

Irrespective of the validity of our hypothesis we believe that the facts presented in this paper strongly suggest a causal relationship between aspirin-sensitive asthma and the inhibition of prostaglandin biosynthesis by aspirin-like drugs. Therefore, inhibitors of prostaglandin biosynthesis should not be given to patients with aspirin-sensitive asthma.

\section{References}

British Medical fournal, 1973, 3, 419.

Daniel, E., and Weber, G. (1966). Biochemistry, 5, 1893.

Flower, R., et al. (1972). Nature New Biology, 238, 104. Acta, 35, 86.

Gregg, I., and Nunn, A. j . 1973). British Medical fournal, 3, 282.

Horton, E. W. (1969). Physiological Reviews, 49, 122.

McDonald, J. C., Mathison, D. A., and Stevenson, D. D. (1972). Fournal of Allergy and Clinical Immunology, 50, 198.

Mathé, A. A., et al. (1973). British Medical fournal, 1, 193.

Pearson, R. S. B. (1963). In Salicylates, ed. A. St. J. Dixon et al., p. 170. London, Churchill.

Samter, M., and Beers, R. F. (1967). Fournal of Allergy, 40, 281.

Samter, M. and Beers, R. F. (1968). Annals of Internal Medicine, 68, 975. Smith, A. P. (1971). British Medical fournal, 2, 494.

Smith, A. P. (1973). In The Prostaglandins, ed. P. W. Ramwell, vol. 1, p. 203. London and New York, Plenum Press.

Takeguchi, C., Kohno, E., and Sih, C. J. (1971). Biochemisty, 10, 2372.

Takeguchi, C., Kohno, E., and Sih, C. J. (1971).
Vane, J. R. (1971). Nature New Biology, 231, 232.

Vane, J. R. (1971). Nature New Biology, 231, 232.
Vanselow, N. A., and Smith, J. R. (1967). Annals of Internal Medicine, 66, 568 .

Yurchak, A. M., Wicher, K., and Arbesman, C. E. (1970). Fournal of Allergy, $46,245$. 